\title{
Age-sensitive eHealth Applications in Smart Homes
}

\author{
Wiktoria Wilkowska *, Philipp Brauner and Martina Ziefle \\ RWTH Aachen University, Human-Computer Interaction Center, Templergraben 55, 52062 Aachen, \\ Germany \\ * Correspondence: wilkowska@comm.rwth-aachen.de; Tel.: +49-241-80 49228
}

\begin{abstract}
Based on the demographic shift and the related challenges resulting from the growing number of elderly and persons with chronic diseases, the idea of smart home that supports its inhabitants in the daily life, gains importance. The purpose of this paper was to examine in a prototypic Ambient Assisted Living environment if users after interaction with different healthsupporting applications intend to use such in the future. Two experimental studies exemplary show possible applications of home-integrated technology that can support, assist and accompany the target group in different contexts, and examine to what extent participants are willing to future use such sophisticated technology at home. The results show that people in general, but especially the old and chronically ill ones are quite fascinated of health-supporting ambient technology and the majority intends to use such ambient assistance in the future (study I). Moreover, serious games for healthcare are shown as a hedonic use of technology in smart homes that have a great potential to retain or improve the physical health, mobility and the overall well-being of the inhabitants (study II). The article provides two examples of ambient technology to leverage the demographic change and presents important user factors for facilitating high user acceptance.
\end{abstract}

Keywords: Ambient Assisted Living; eHealth; Technology Acceptance, Smart Health, User Diversity, Serious Games for Healthcare

PACS: J0101

\section{Introduction}

\subsection{Motivation}

One of the largest and powerful trends of our time is the global demographic transition resulting from the changes in population structures of many nations [1]. The additions are distributed unevenly across the world reflecting the existence of substantial heterogeneity in birth, death, and migration processes. According to the statistics of United Nations, by the end of 2011 the world's population has increased to over 7 billion people and is projected to reach 9 billion by mid-century. Thereby globally, population aged 60 years and over is growing at the fastest pace [2]. While the world population is projected to be 3.6 times as large in 2050 as it was in 1950, the number of persons who are 60 and over is expected to increase by a factor of 10, and those 80 and over will increase by a factor of 27 [1].

Some of the entailed consequences of these future demographic trends have been widely discussed, but much is still unknown about how population shifts will affect the different areas of life. The rapid population ageing and the changes referring to the development of the main drivers of the demographic change (fertility decline, increasing life expectancy, and migration) trigger complex social, political and socio-economic consequences many nations find themselves confronted with. Such challenges in various public spheres require effective, innovative and efficient solutions. Consequently, profound changes in the family structure, health, and institutions for saving and supporting retirement already are or will be set in motion in the near future. Financing of social insurance systems is strained and the policymakers face difficult decisions about changes in benefit 
structures and taxes for supporting the graying society. In addition, it is less certain how economies will respond to the demographic transition, and how policies will affect the global flows of labor and capital in the economic development [3].

The globally increasing number of people aged 60 years and over as well as the growing life expectancy results in an increased likelihood of (chronic) diseases, which are associated with the old age. This fact is connected to a substantial increase of costs in the area of healthcare and nursing services [4]. It goes without saying that older individuals require on an average more services from the healthcare system in comparison to the younger ones, contributing at the same time comparably less to the insurance funds. In the long term, this leads to a declining revenue base of insurance, while the expenditures on healthcare are going to considerable rise in the future.

In addition to the financial bottlenecks due to increased treatment and nursing requirements on the part of the elderly generation, some issues from the medical supply chain arise. In the last decades, several weaknesses in the German healthcare system became apparent [3,5]. A combination of lower fertility rates and higher longevity of the society results in the consequence that the number of persons who need (nursing) care is significantly higher than the number of these, who can offer the health support. For instance, a physician shortage cannot be longer overlooked: Besides primary care physicians, especially specialists (e.g., cardiologists, orthopaedists, gerontologists) are mandatory particularly for older patients who require two to three times the amount of specialty care to treat chronic conditions and age-related illnesses. The same applies to the nursing staff.

Moreover, the basic family structure has been reshaped over the last decades and the support as caregivers from this side is also not that much promising: Today many people live alone, families are smaller, marriage is no longer "obligatory", the values for children have altered, and within the partnerships the gender roles become less traditional [6]. Accordingly, the traditional obligations towards the elderly relatives (e.g., nursing at home in case of chronic illness) became less compulsory.

The effects of the from demographic shifts resulting deficiencies on individuals have mostly unpleasant consequences. Therefore, not only for the general health improvement of the population, but also to save expenditures in the health context, long-term prevention measures, constant health monitoring and early diagnostics gain much more importance. To prevent the greying society as far as possible from the onset of chronic illnesses is the first step to generally achieve better health and at the same time to reduce health-related costs. To achieve this, for instance targeted prevention programs regarding fitness and/or diet regulation can be realized already in the young age of individuals. On the other side, for those who already suffer from chronic condition, a powerful disease management must be established (i.e., sensible, as far as possible unobtrusive monitoring of the relevant vital parameters and a continuous dialog with a supervising physician) and an efficient system must be created for an integration between the supply structures as well as inpatient and outpatient, curative, rehabilitative and nursing services.

One possible solution to achieve such ambitious goals lies in the use of the technology, or more specifically, of advancements in ubiquitous computing in combination with sophisticated intelligent sensor networks [7]. Modern technologies which are integrated in home environments have huge potential to assist elderly and individuals with chronic conditions in their daily life, to support their independency, sovereignty and autonomy, as well as to maintain the comfort of living in familiar surroundings instead of moving to a nursing home or long-term rehabilitation clinic. Technologies which support the health, wellbeing, a balanced and satisfactory lifestyle, be it a sport program, serious exercise games or vital parameter monitoring system that are adapted to the inhabitant's needs, are feasible today and can be well realized.

The topic electronic health (eHealth), describing a fusion of medicine and healthcare services through the use of information and communication technologies, with particular focus on everyday life and low cost devices $[7,8]$, is currently a top theme, in particular because of its wide range of various application possibilities and thus benefits for the heavily overstrained healthcare sector. Also, electronic homecare (eHomecare), focusing on preventive care applications in home environments and offering a wide range of services (e.g., patient assessment, supervision of patient care, routine 
nursing care and health monitoring, medication administration and scheduled injections, dietary management, and preventive exercise [9]) has in this context presumably a great future.

In the areas of health prevention, cure, and rehabilitation, eHealth technology and eHomecare provide for both, the users and the healthcare meaningful framework that is worth to be user-centred researched. Taking as an example the diseases with the highest prevalence in society, the cardiovascular diseases (e.g., acute cardiac infarction, cardiac insufficiency, disturbed blood flow through cardiac muscle) are the leading cause of death in Germany, causing a total of about 40 percent of all deaths [10]. According to the experts, people who had suffered from a cardiovascular disease are, firstly, urged to regularly monitor their vital signs, such as blood pressure, heart rate, body weight, temperature, and coagulation. Unfortunately, current practice in aftercare frequently requires the patient to take their vitals with commercially available medical devices individual to each parameter, write down the values each day on paper, and mail or fax it to the physician once a month or more often in case of frequent irregularities [11]. Secondly, persons with serious cardiovascular diseases under certain circumstances must strictly comply with their medication, follow special dietary requirements and absolve trainings to maintain physical health. Therefore, eHealth technology embedded in the home environment could assist in many of these obligations, which are commonplace for (older) heart patients or vulnerable persons in this regard, or completely take over a part (e.g., the storage and transmission of the health data), and govern it for the people (e.g., regular consultations with the attending physician).

To reach a successful adoption of such health-supporting technology, however, high acceptance, a high perceived meaningfulness of its use and therefore high intention to use are needed. According to the Extended Unified Theory of Acceptance and Use of Technology Model [12] the use behaviour is directly linked to the behavioural intention to use a technology system, and this one is modelled by different influencing factors, like among other things by the expected performance, hedonic motivation, and social influence; and it is moderated by user diversity factors, like age and gender. In the presented research studies, a special attention is dedicated to these factors.

\subsection{Future Care Lab ${ }^{\odot}$ and Its Applications}

A prototyping technical environment was created in the Future Care Lab ${ }^{\odot}$ at the RWTH Aachen University. The idea was, to make use of the currently on the market available technologies and integrate them into an overall consistent usage concept. Thus, the Future Care $\mathrm{Lab}^{\odot}$ was meant to be a medical and a living environment at the same time, this is, the room should on the one side provide the necessary medical equipment and assistance features without compromising the comfort, and on the other side preserve the intimacy and the personal privacy of a living room [11]. For the communication interface which is the key requirement for remote diagnostics and the communication between the patient and physician, the room was equipped with high-definition cameras and a wall-sized interactive display like presented in the Figure 1. The multi-touch sensitive display wall serves as a screen and an input device for various applications [13, 14] ranging from monitoring of relevant health parameters, medication, nutrition, and exercise management to daily multimedia entertainment (e.g., serious games [15], movies) or virtual environments (e.g., myGreenSpace, meetingMeEating [16]) or meetings with physicians or family and friends [17, 18]. Focusing on the health aspect, this feature allows the inhabitant to measure the bodily functions, easy access of their vital data and medication histories without using different devices and troublesome writing down and store the results for a (video) consultation with the physician. 


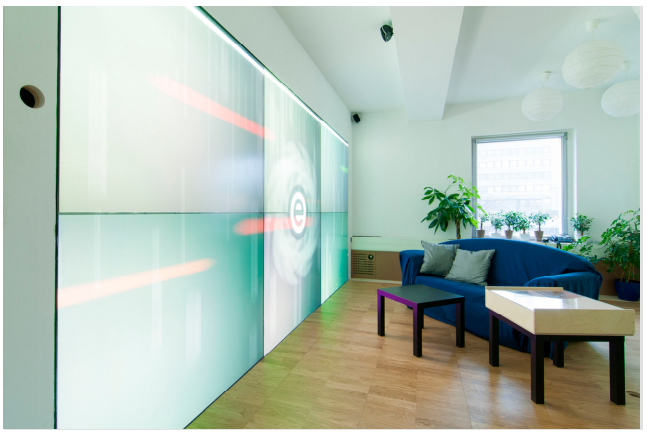

(a)

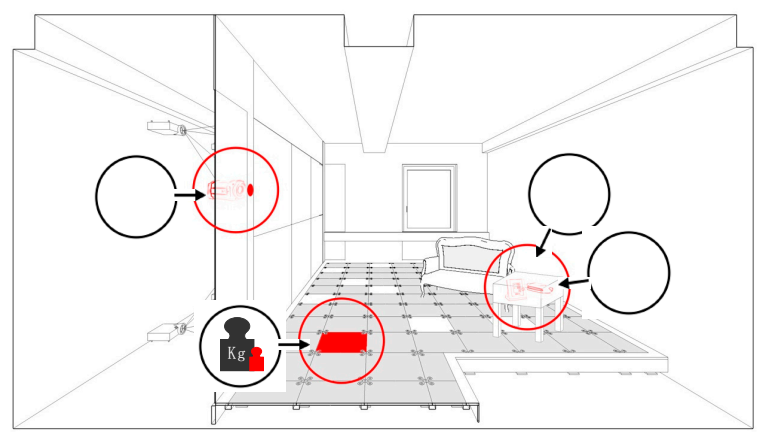

(b)

Figure 1. Future Care $\mathrm{Lab}^{\odot}$ with its interactive wall display, serving as the visual communication tool and a diagnostic interface in the patient-doctor-communication: (a) unobtrusive interior of the living lab environment, (b) schematic visualization of the health monitoring system (side table: blood pressure and coagulation; wall: body temperature; floor: weight).

A meanwhile popular term of Ambient Assisted Living (AAL) describes the basic idea behind the development of the living lab: A space to foster the emergence of systematic innovation for an autonomous living of elderly and individuals with chronic illnesses which, on the one side, increases the quality of their lives, and on the other side, reduces the expenditures of the possibly necessary nursing care. Such smart homes that include innovative smart health concepts reaching from electronic health monitoring to serious gaming, are meant to be individually suited to the resident(s), adaptive, according to the (changing) needs (e.g., disease progress) and sensitively with regard to the living conditions.

\subsection{Overall Research Goals}

The main aim of the current paper is to show our idea of a smart home, an environment that contains uncomplicated technology applications merged to one ubiquitous system that can simplify its users' life in different areas. For that purpose, we introduce Maria, who is an (imaginary) prototypic inhabitant of the smart home. Maria is one of several archetypic personas [19] that guided the design and development of the Ambient Assisted Living Lab between the participatory user studies. In this article, Maria will guide the reader through the novel components of her technology augmented living room. She is 74 years old, living alone, and as a result of a cardiac infarction which she suffered from a few years ago, she must regularly check some of her bodily functions (i.e., blood pressure, weight) and consult her doctor at certain time intervals. There are additionally some agerelated mild physical impairments, but she is generally in quite good health condition and interested in maintaining her independence in 'the own four walls'.

Two exemplary studies will be subsequently reported to show meaningful health applications for persons in similar situation and with comparable ailments as Maria. In the first study, a health assistive application that is embedded into the living environment and allows to monitor relevant vital parameters is evaluated and the intention to use the health-supporting ambient technology after an interaction with the system is the subject of interest. The second study reports an experimental setup with a more hedonic context: Serious games in the technology augmented habitat. Here, apart from the rendered performance and factors influencing the willingness to play the game, factors influencing the intention to use the ambient technology in the fun context will be presented.

\section{Study I: Health Assistance at Home}

In the first study, it was examined if potential users after a real interaction with the healthsupporting application would be willing to use such assistive system at home in the future. For this purpose, an experimental study with middle-aged and older individuals was performed in the Future Care $\mathrm{Lab}^{\odot}$. The intention was to study persons with chronic heart conditions who have to daily monitor some of their health parameters, and to compare their opinions to individuals without any health ailments. 
Getting back to the example of Maria, the main question was if she would intend to use applications which would simplify the measurement of her vital parameters as well as ease the storage of her sensitive health data and the communication with the responsible physician in case of deterioration of the relevant values. In the following, the experimental design and procedure are described.

\subsection{Materials and Methods}

\subsubsection{Research method}

As the aim was to get an impression of the real use of the assistive system, this study was designed to examine how persons with chronic heart conditions can effectively monitor their relevant vital functions by means of unobtrusively integrated specific medical devices in a domestic environment.

For this purpose, the participants were asked to perform in the Future Care Lab two for the heart patients' exemplary measurements. The first was the measure of blood pressure (via a standard sphygmomanometer, comprising an inflatable cuff to restrict blood flow and a manometer to measure the pressure), and the second was a weight measurement (via a digital scale integrated in the floor) as both according to experts are reliable parameters for (negative) changes in cardiovascular processes in the human body. Participants were requested to use a health-app of the system (see Figure 2) which allowed to initiate the particular measurement and afterwards to appropriately save the data in the system, and to compare the current result with the previous results (imaginary but strongly related to the real one) in a measurement overview.

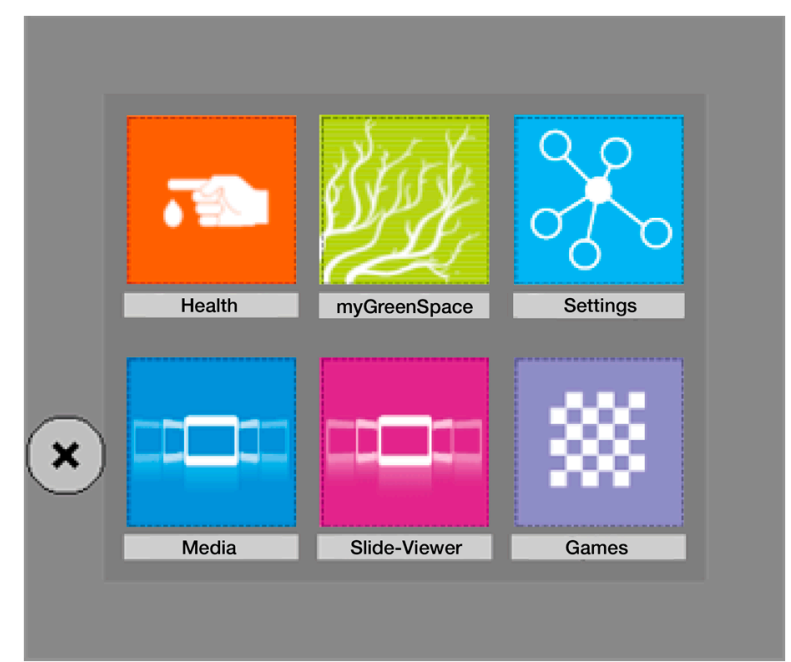

(a)

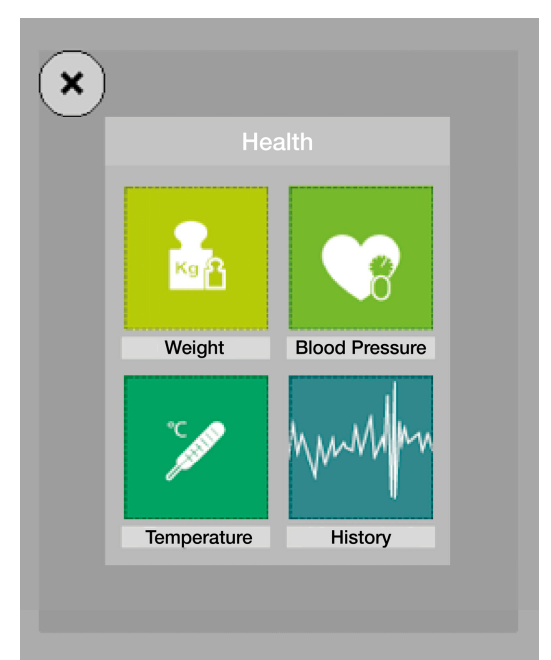

(b)

Figure 2. Control panel on the large wall screen in the Future Care Lab ${ }^{\odot}$ : (a) Front panel for different applications; (b) The health-app tailored to Marias needs of monitoring vital parameters relevant for the cardiovascular system.

Between the particular trials and after the interaction with the health related application of the system, individuals were asked to assess if they would use such sophisticated technology equipment at home, provided that the framework conditions are acceptable (i.e., transparent financing, technical maintenance, telemedical servicing). In a semi-structured interview as well by the method of a quantitative questionnaire participants answered to questions like e.g., "Can you imagine to use at your home an eHealth system like this in the future?"; "I think, I would like to frequently use such technology system in the future". The statements in the questionnaire had to be rated on a five-point scale that ranged from "strongly disagree" $(=1)$ to "strongly agree" (=5). In addition, opinions about the system's usability assessed by the System Usability Scale [20] and general perceptions with regard to reliability of the system, data security and personal privacy were collected (for details see [3]). 


\subsubsection{Experimental Procedure}

The experimental testing was carried out in a period of about two weeks. The sessions were held individually and in German, which was the native language of all participants. Before the experiment started, each participant was interviewed, whether she or he had special needs, any objections or restrictions with respect to the planned study. The experimental trials took on average $20-30$ minutes.

In the first step, the examined person was introduced to the concepts of Ambient Assisted Living and telemedicine to give her an idea of the broad possibilities connected to eHealth technology in domestic environment: monitoring of vital parameters in comfortable way at home and the remembering function to do so, efficient digital transmission of the sensible health data, facilitated the patient-physician communication and exchange with other patients and/or support groups on the Internet. To evaluate the interaction with the technology, participants had to perform two tasks, which were the measurements of the blood pressure and body weight as described above, using the health-app of the system. Each action was previously demonstrated by an experimenter. After each measurement, the participants were requested to interact with the app by taking a look on the weekly or monthly overview of the particular results (the fictitious values for the previous weeks and months were generated automatically, using an algorithm based on the real measurement). In the time of interaction, persons were informed that the storage and the transmission of the personal health data should take place via secure specialized medical services, which would facilitate the communication with the medical stuff. There were no time limits for the user's interaction with the health-app. After each measurement and the subsequent interaction participants had to evaluate the usability and the intention to use the system.

In the next step, participants filled in the questionnaire comprising of questions about the functionality and usability of the system, as well as the assessments of the willingness of the future use (see section 2.1.1.)

In the final part of the experimental session, interview with the test person should give the possibility to comment on the perceived advantages and disadvantages in comparison to the current solutions in the healthcare sector, and the general attitude toward future use of such complex and sophisticated technologies in the domestic setting was enquired.

\subsubsection{Participants}

The acquisition of participants for this experimental study occurred through posters in local hospital in the sector of heart diseases as well as in public places, and it took about three weeks.

A total of 25 middle aged and older German adults between 35 and 86 years of age (M=61.1, SD $=12.4$ ) participated in the study and $56 \%$ of them were females. More than a half of the participants $(52 \%)$ reported suffering from some kind of chronic heart disease (e.g., tachycardia, myocardial infarction, coronary heart disease), and as many to regularly visit a physician to check their actual health status. In the group with chronic conditions (CC) all persons used medical assistive devices in order to monitor some relevant vital signs (e.g., blood pressure, heart rate, weight, body temperature); the majority ( $70 \%$ ) of them wrote down the results of measurements by pen and paper. In the group with healthy participants $(\mathrm{H})$ only one person reported using medical devices, and to visit physician periodically for checkups.

The participants represented different educational levels: $52 \%$ of them reported an university degree (amongst other things business administration, domestic science and nutrition, psychology, mechanical engineering, teaching profession, biology, etc.), 20\% completed a vocational education, and $28 \%$ indicated elementary and secondary school graduation. When asked about the current, or profession before the retirement, various occupational fields turned up, e.g., psychologists, practice nurses, engineers, administrative assistants, teachers, business economists, translators, etc. In this way, the presented study reflects a broad spectrum of users. The attendance at the experiment was voluntary and was not compensated with payments or other incentives, except careful efforts to the physical well-being. 


\subsubsection{Research Variables}

In order to examine the intention to future use of eHealth technology in different users, following research variables were involved in the statistical analyses.

- Independent variables:

The first independent variable was the age of the tested persons. Here, the middle-aged (age range: $35-59$ years; $M=51.4, S D=6.6 ; n=13$ ) and people of the older adulthood (age range: 60 86 years; $M=71.6, S D=7.7 ; n=12)$ were compared. In addition, the participants' self-reported health status [chronic heart condition $(n=13)$ vs. healthy/without heart condition $(n=12)$ ] distinguished between the participants. And also, gender-specific perceptions [males $(n=11)$ vs. females $(n=14)$ ] were envisaged in the analyses.

- Dependent variables:

The main focus lies on the intention to future use of the complex, and at the same time versatile technology which is (unobtrusively) integrated into the residential area. Methodologically, this topic is considered from both the qualitative and quantitative point of view. In the quantitative analysis, the two assessments about the intention to use eHealth in the future which were evaluated after each measurement event, were merged and form a single variable (ItU: $\min .=2$, max. =10). The other dependent variables are the fun ("I had fun to use the system") and the perceived meaningfulness of the use ["I consider the monitoring of my vital parameter (e.g., blood pressure and weight) with the help of integrated technology at home reasonably"]. The latter two had to be rated on a five-point scale as described above.

\subsection{Results}

The results to be presented in the first study, focus mainly the users' intention to use complex assistance technologies in the smart home environment that is exemplified by the health context, alluding to the burden of increasing numbers of older and persons who need medical monitoring. In the following, it is firstly analyzed how the intention to use such eHealth technology is correlated to the simple fun of the use and its perceived meaningfulness, and how all research variables are connected. Secondly, it will be examined whether there are fundamental differences between the users which either promote or prevent the decision about the intention to use the system. And thirdly, a qualitative analysis will give us a complementary picture of the opinions about the intended future use. The cut-off for the significance level in all statistical analyses lies by $5 \%(p=0.05)$, the effect size is calculated with eta squared $\left(\eta^{2}\right)$, the values of which can range from 0 to 1 and are interpreted with regard to the strength according to the following [21]:

- .01 = small effect: the effect explains about $1 \%$ of the total variance;

- .06 = moderate effect: the effect accounts for $9 \%$ of the total variance;

- large effect: the effect accounts for about $25 \%$ of the variance.

\subsubsection{Relationships Among the Research Variables}

To gain a general impression about the associations between the research variables, Pearson product-moment correlation coefficients (parametric analysis between the continuous variables) and Spearman's rho correlation coefficients (non-parametric alternative) were generated. Table 1 summarize the strengths of the particular relationships. 
Table 1. Bivariate correlation coefficients between the research variables (gender: male $=1$, female $=$ 2; health status: healthy $=1$, chronic heart condition $=2)(N=25)$.

\begin{tabular}{l|cccccc}
\hline & Age & Gender & Hs & ItU & F & M \\
\hline Age & 1 & - & $.48^{*}$ & $.53^{* *}$ & .13 & $.40^{*}$ \\
Gender & & 1 & - & -.07 & .15 & .09 \\
Health status (Hs) & & & 1 & $.43^{*}$ & -.15 & .22 \\
Intention to Use (ItU) & & & & 1 & $.49^{*}$ &. $\mathbf{4 2}^{*}$ \\
Fun (F) & & & & & 1 & $.3^{* * *}$ \\
Meaningfulness (M) & & & & & & 1 \\
\hline
\end{tabular}

${ }^{* * *} p<0.001 ;{ }^{* *} p<0.01 ; * p<0.05$

From the results of the correlation analysis it is evident that age is strongly associated with the intention to use the ambient technology $(r=.53, p<0.01)$ and with the meaningfulness of the use $(r=$ $.40, p<0.05)$, which means that both are higher with the increasing age. Not surprising is the fact that with increasing age grows the occurrence of the chronic heart diseases $(r=.48, p \leq 0.01)$, but there is also a substantial positive association with the intention to use the eHealth technology $(r=.43, p<$ 0.05): Persons with chronic heart condition show higher willingness to use it in comparison to the healthy participants. In contrast, for gender there is no evidence of links to the focused aspects (n.s.).

From the Table 1, high positive relationships between the focused dependent variables become evident. The intention to use the technology is positively related to the perceived meaningfulness of the use $(r=.42, p \leq 0.05)$ and fun $(r=.49, p \leq 0.05)$; the latter two in turn are strongly associated with each other $(r=.63, p \leq 0.001)$. These substantial relationships among the target variables give rise to take a closer look at the effects of different users on the future usage behavior in the health context.

\subsubsection{User Differences}

After the consideration of the rough data structure based on the above correlations, in the next step the effects of the independent variables on the intention to use, fun and the perceived meaningfulness with respect to the use of ambient health-supporting technology are examined carefully. To compare the research groups according to the properties of the data, independentsamples $t$-tests were used.

Since in the context of eHealth technology the physical health of the inhabitants can be decisive for the opinion about the use, the first analysis refers to the comparison between persons with chronic heart condition and healthy individuals. Significant differences appeared with respect to the intention to use eHealth in the future between the named research groups $\left[t(23)=2.3, p=0.033, \eta^{2}=\right.$ $0.17]$. Those who have to suffer from an illness in their daily life wanted almost without exception to use the technology in the future $(M=9.7$ out of 10 points, $S D=0.6)$. In the healthy group the opinions in this regard were positive too, but much less pronounced $(M=7.7, S D=3)$. The mean differences are depicted in Figure 3. Apparently, all persons have a positive attitude towards the technology innovation as the average values are high. However, people with chronic diseases see still more benefits in the use of the technical assistance (at least in the context of the health-app) in comparison to the persons without any permanent ailment. Moreover, the health status had no significant effects with respect to the perceived fun with the technology $[t(23)=1.1, n . s$. $]$ and the perceived meaningfulness of its use $[t(23)=1.2, n$.s. $]$. 
Intention to Use $(\max =10)$

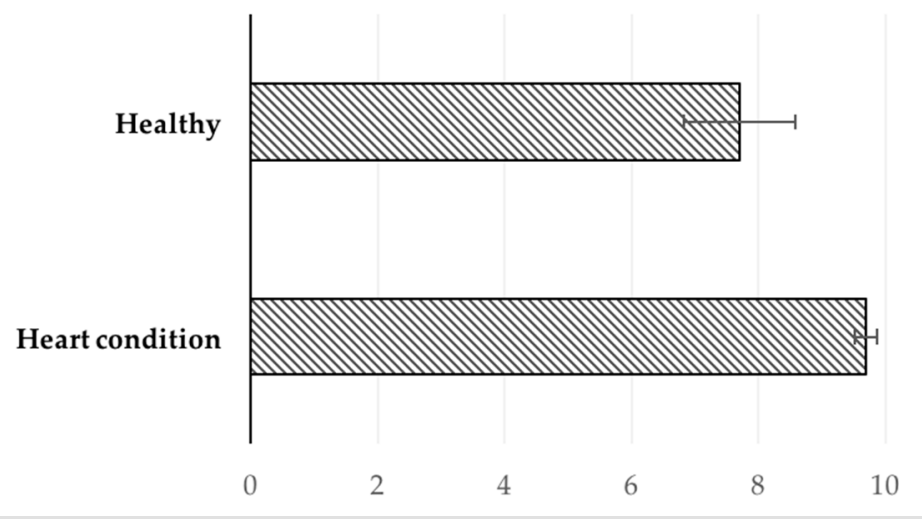

Figure 3. Main effect of the health status on the intention to use eHealth technology at home $[t(23)=$ $2.3, p<0.05]$.

In addition to the health aspect, it is also of interest, whether the factor age influences the opinions about the aspects of the willingness for future use of medical assistance system in the home environment. The analysis revealed that the examined age groups significantly differed in regard to the intention to use $\left[t(23)=-2.5, p=0.025, \eta^{2}=0.22\right]$ and the perceived meaningfulness of the use [ $t(23)$ $\left.=-2.9, p=0.012, \eta^{2}=0.26\right]$. Here, persons in the group of older participants showed averagely higher, almost the maximum possible intention to use eHealth $(M=9.8$ out of 10 points, $S D=0.4)$ and considered the monitoring of their vital parameter by means of the medical assistive system invariably more meaningful $(M=5$ of 5 possible points, $S D=0)$ than the middle-aged individuals (ItU: $M=7.8, S D=2.9$; meaningfulness: $M=4.4, S D=0.7$ ). In Figure 4 the effect of age is visualized. With respect to the evaluations of fun after the interaction with the system, both age groups showed high mean values (middle-aged group: $M=4.6, S D=0.8$; old age group: $M=4.8, S D=0.4$ ) and the differences were not significant $[t(23)=-0.9$, n.s. $]$.

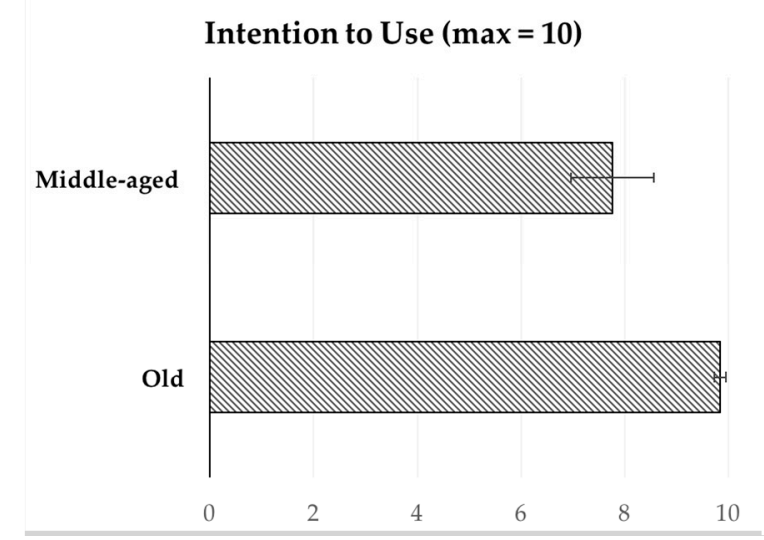

(a)

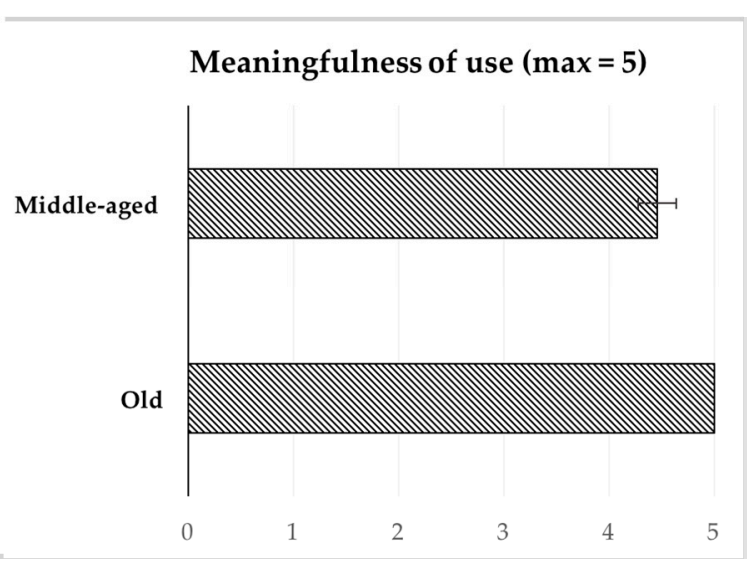

(b)

Figure 4. Main effect of age: (a) on the intention to use eHealth technology at home $[t(23)=-2.5, p<$ $0.05]$; (b) on perceived meaningfulness of the use $[t(23)=-2.9, p<0.05]$.

In the final step, it was examined if the factor gender influences the opinions in relevant way. The independent-samples $t$-test analysis revealed no statistical significance for the gender differences [ItU: $t(23)=-1$, n.s.; fun: $t(23)=0.6$, n.s.; meaningfulness of use: $t(23)=0.7$, n.s.]: Men and women reached similarly high mean values in all the mentioned aspects. These results testify that unlike previous technology generations gender no longer splits the users with respect to the latest technological achievements. On the contrary, women and men are equally willing to use, have 
comparable fun with, and they consider the technical medical assistance at home to the same extent meaningful.

\subsubsection{Intention to Use eHealth: Qualitative Analysis}

To complement the research analysis, in this section a brief report of qualitative results will additionally take place. The benefits of the qualitative methods like interview are not only a far more personal form of research, but also, working direct with the respondent eases the expression of opinions and impressions, and it allows to ask follow-up questions or adjust if someone strays from the topic.

As it was described in paragraph 2.1.2., after the interaction with the ambient assistive system in the Future Care Lab and the subsequent filling-in the questionnaire, participants were involved in a short semi-structured interview. Therein, they had to respond among other things to the question, whether they could imagine (or not) to use at their homes in the future a technical system, like the one shortly used before.

According to the finale statements, more than two-thirds of the participants ( $n=19 ; 76 \%)$ showed a very positive attitude towards the (future) use of the system after the interaction with the prototypic eHealth environment. In the following, some exemplary statements are listed:

- "I find it totally good! Luckily, until now I hadn't to deal with bigger health issues, but I think that has a future and I can imagine to use it not only in the health context." (male, 53 years, no chronic conditions)

- "I think, when the technology is fully developed and it works properly, the results of the measurements would be absolutely reliable. If I had that, I would also regularly measure my blood pressure, like I anyway should. In this form it is too large for my apartment, but I find it great and I would definitely use it in the future." (female, 56 years, hypertension)

- "That's really interesting and is also fun! I could use it very well." (female, 73 years, no chronic condition)

Another $20 \%$ of the interviewed persons $(n=5)$ showed positive attitude, but they also showed certain skepticism or declared the future use with some reservation. Below an example:

- $\quad$ "You certainly can learn how to use that thing, but most people are reluctant to deal with it; my wife, for example. I find it very good, however, space limits and the financing could be reasons not to use it." (male, 74 years, cardiac insufficiency)

- "I think it's great that you can operate with the whole hand (instead of only one finger). But I would like to see additional functions: electronic calendar, reminder, etc. You could also retrofit the floor." (male, 71 years, myocardial infarction, stroke)

One person rejected the use of the ambient system in the future:

- $\quad$ "Human contact gets lost, the sense organs come off badly, life would be very mechanized. That's not for me! I'm less afraid about my health monitoring than about the [social] isolation. "(female, 58, arrhythmia, tachycardia)

\subsubsection{Summary of the results}

According to the presented results, the greatest enthusiasm for the use of health-related technology in terms of ambient assistance systems in domestic environment emerges from the elderly and chronically ill people. Their intention to use such ambient technology is significantly higher than in healthy and individuals in their middle ages, even if the vast majority of the participants acknowledges it as a meaningful and enriching supplement. All participants invariantly show great 
fun with the technology, reaching mean values between $M=4.6$ to $M=4.8$ out of maximum five points. In addition, the absence of significant effects in terms of gender indicates that women and men comparable evaluate the technology with respect to the here focused aspects.

Accordingly, we can assume that Maria is very pleased with the surrounding technology in her home and even enjoys the regular measurements of her vital signs. She definitely wants to use this innovation in the future further.

\section{Study II: Valuable Fun at Home: Serious Exercise Games in AAL}

After the measurement of her vital parameters, Maria is interested in playing a game. The technology augmented habitat provides different types of games. Maria can choose to play conventional computer games, or she might play with one of the several serious games for healthcare, the Ambient Assisted Living environment offers. Serious game couples the motivational incentives of games with explicit and thought-out purposes outside the actual game [22]. For example, the game Cook It Right [23] uses a cooking scenario to address the improvement of cognitive functioning, i.e., remembering and planning abilities. Yet, Maria decides to launch the exercising game.

Physical inactivity is linked to diabetes, hypertension, coronary and cerebrovascular diseases and it is also connected with a lower life expectancy [24]. In contrast, exercising has benefits for health, such as lower risk and lower intensity of cardiovascular diseases [25], higher physical and cognitive abilities [26], as well as positive influences on mood and depression [27]. Also, sportive physical activities reduce the probability of silent brain infarcts [28]. Therefore, performing regular exercises - in or outside a game environment - is beneficial for increasing the health status.

The game involves full-body movement exercises captured with nearly invisible motioncapturing cameras and aims at fruit picking in a garden environment presented on the large wall of the technology augmented habitat [15] (see Figure 5), as this was identified as a suitable game core by previous research [29]. In several levels with increasing difficulty, distinct movement gestures address different body and muscle areas and the training should retain or improve the overall stamina of the players. The game offers different single and multiplayer modes, and the players can decide to compete against their own high scores or against the others over a network. Today, Maria chooses to play the single player mode, as she wants to break her personal record for the levels with more difficult movements.

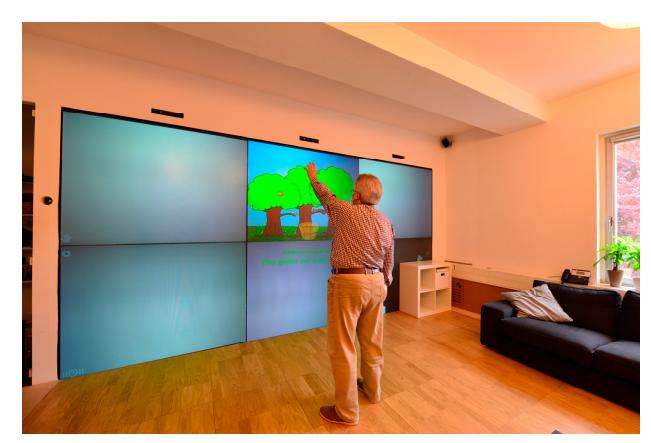

Figure 5. An elderly player interacting with a prototype of the fruit picking game.

\subsection{Materials and Methods}

To investigate, how people interact with an exercise game in a technology augmented environment, and to understand under which conditions they are likely to be used, a formal user study was conducted. The next section presents the evaluated prototype of an exercise game, followed by the description of the independent, explanatory, and dependent variables. Finally, the sample of the experimental study is described.

\subsubsection{The Evaluated Game Prototype}


In the exercise game, the player's task is to pick different fruits (e.g., apples, pears) in a comiclike garden environment presented on the large wall of the ambient assisted living lab. The body movements are captured through the hidden Kinect Sensors which captures a high resolution color image, a depth image, as well as a skeleton model with the $3 \mathrm{~d}$ coordinates of 20 joints with high temporal and spatial resolution. In contrast to the most other games, the picture of the player is directly integrated into the game environment by compiling the several images from the Kinect sensor (see Figure 6): The RGB image of the player is separated from the background by using the depth image, then the background-separated image is integrated into the game's scenery.

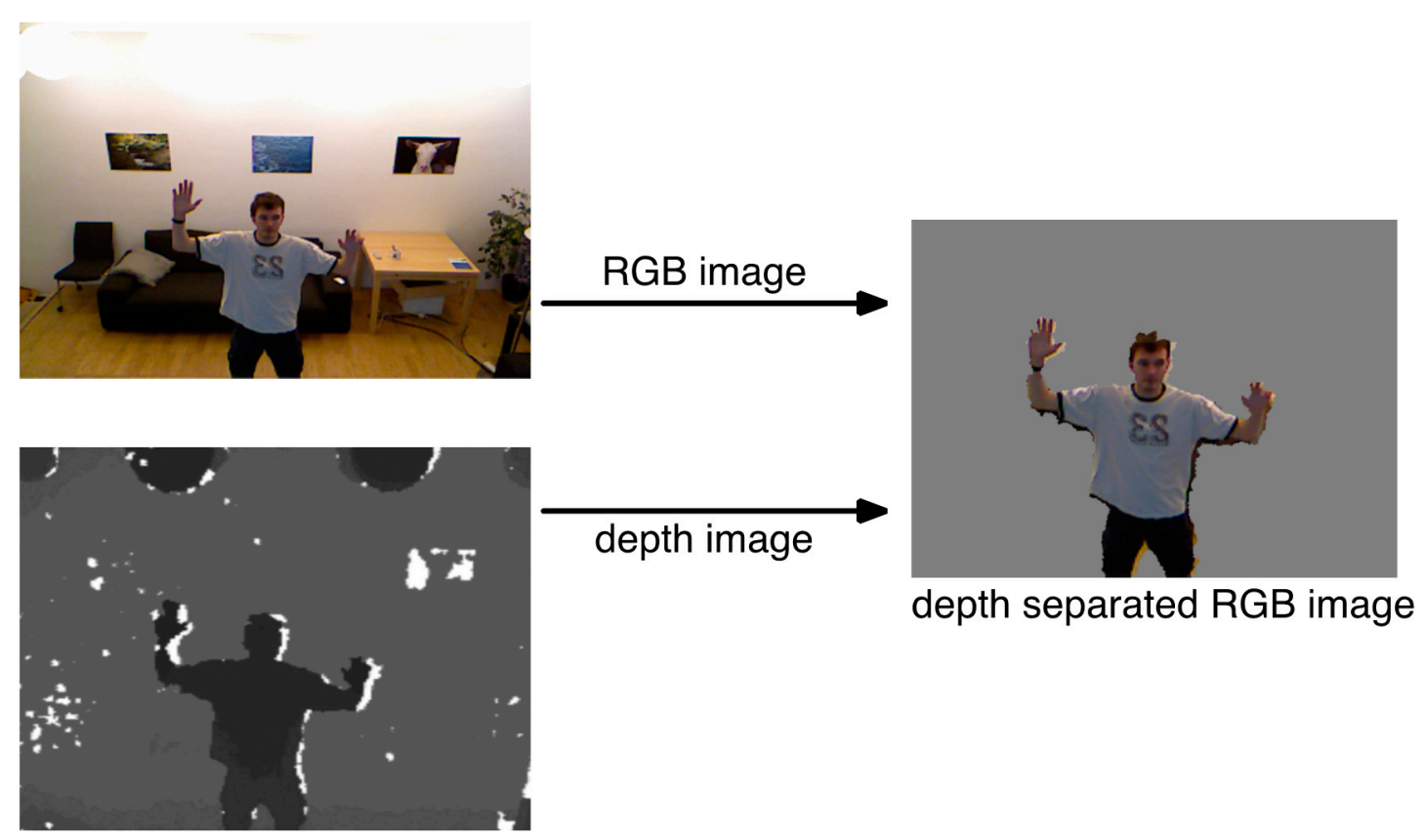

Figure 6: Schematic illustration of the separation of the player's background using the depth image.

For each type of fruit, a specific full body movement gesture is required. The gestures were developed with medical professionals and each gesture captures a specific, medically sound, exercise. For example, for picking an apple on the right side of the screen, the left hand must be used. This trains the hand-eye-coordination and the shoulder and back muscles. During the first levels of the game, the different gestures are sequentially introduced and repeatedly trained by the players.

The game offers various modes of play, for instance, single player in which the user can compete against an individual or shared high score, co-located multiplayer levels, and also play over a distance. In the last variant, the picture and audio output of the players is transferred over a network and displayed on the other side of the wall.

\subsubsection{Research Variables}

Before and after the serious game intervention, a questionnaire assessed the independent (explicitly used for creating the sample), explanatory (measured, but not used for creating the sample), and the dependent variables (capturing the evaluation of the game) of the user study.

- Independent variables:

Besides age and gender as independent variables, the questionnaire collected data regarding the participants' self-efficacy in interacting with technology (SET, e.g. "I have fun solving technical problems."), their gaming frequency across multiple game types (GF, e.g., "I frequently play board games."), and their need for achievement (NAch, e.g., "I am attracted to difficult problems."), as additional explanatory variables. 
Self-efficacy in interacting with technology relates to Banduras Self-efficacy Theory [30] and describes an individual's perceived ability to successfully interact with a technical device and to attain certain goals with these devices. Previous research has identified tremendous gender (e.g., [31-33]) and age effects (e.g., [34, 35]) in performance in and acceptance of technological systems. Self-efficacy in interacting with technology was measured and analyzed by the scale of Beier [36].

Gaming frequency was determined as an index across nine playful activities ranging from the playing card or ball games (not computer mediated) to the computer or console games.

The participants' need for achievement was measured on a scale by Schuler [37]. An individual's need for achievement relates to the choice of tasks and the performance attained in the tasks. Therefore, players with higher need for achievement will attain a higher performance in the game than players with lower need for achievement.

- Dependent variables:

In addition to the aforementioned personality traits, the participants' subjective pain levels for several body regions (e.g., head, shoulder, back, legs) and the perceived current level of exertion - collected through the scale by Borg [38] that strongly correlates with the actual heart rate - were explored. To investigate the effect of the game on the perceived pain and exertion, both measures were captured directly before and after the game intervention (repeated measure).

The evaluation of the game was measured using the items of the Technology Acceptance Model [39] and the Extended Unified Theory of Acceptance and Use of Technology (UTAUT 2) [12]. Following Davis' TAM model [40], there is a strong relationship between the intention to use a system and the later actual system use. Therefore, the intention to use (ItU) is captured as the target variable to predict the actual use of the system (e.g., "I would like to use this game in the future."). A detailed description of the other constructs of UTAUT 2 for this exercise game is given in [15].

In addition to the participants' assessments of the game, the attained performance was captured via log files and then combined with the data from the questionnaires.

All items besides age and gender were rated on 6-point Likert scales from 0 ("I fully disagree") to 5 ("I fully agree"). The acquired data is analyzed using bivariate correlations [Spearman's rho $(\rho)$ coefficient is reported], univariate analysis of variance (ANOVA) and repeated measures. Effect sizes are reported as $\eta^{2}$ corresponding to the first study. Multiple linear regressions were calculated using the step-wise method and models with high variance inflation factors were excluded (VIF $\gg 1)$. The level of significance is set to $p=.05$.

\subsubsection{Participants}

In total $N=64$ participants ( $n=32$ males and $n=32$ females) ranging in age from 17 to 85 years participated voluntarily and without financial compensation in the user study. The participants were gathered through public posters in the city and personal social networks. The reported current or last occupation were in the social $(20 \%)$, health $(8 \%)$, business $(9 \%)$, technical $(41 \%)$, or other sectors $(22 \%)$.

As above, the sample was split into a younger (age $<35$ years) and an older group (age $>35$ years) to differentiate younger and older participants' evaluations using factorial methods. By design of the sample, age group and gender were not correlated $\left[\chi^{2}(64,2)=.563, n . s.\right]$.

About a quarter of the participants (26\%) reported a chronic illness, mainly asthma, hypertension, diabetes and the prevalence of chronic illness increases with age ( $\rho=.41, p \leq .001)$. 
Elderly subjects report a lower technical self-efficacy $(\rho=-.37, p<.01)$. Also, gender affects technical self-efficacy and women report significantly lower scores than men $(\rho=-.33, p<.01)$. Gender $[F(60,1)=4.3, p=.043]$, as well as age group $[F(60,1)=24.6, p<.001]$ is significantly related to technical self-efficacy. Though, there is no significant interaction between the age and gender $[F(60,1)=0.1$, n.s.].

The subjective gaming frequency decreases with age $(\rho=-.49, p<.001)$, but gender did not affect the reported gaming frequency $(\rho=-.16, n . s$.$) . Although the gaming frequency scale captures the$ frequency of use of technology-mediated and non-technology mediated playful activities, there is a strong positive relationship between gaming frequency and self-efficacy in interacting with technology $(\rho=.60, p<.001)$.

Figure 7 depicts the dependencies between the various investigated user factors.

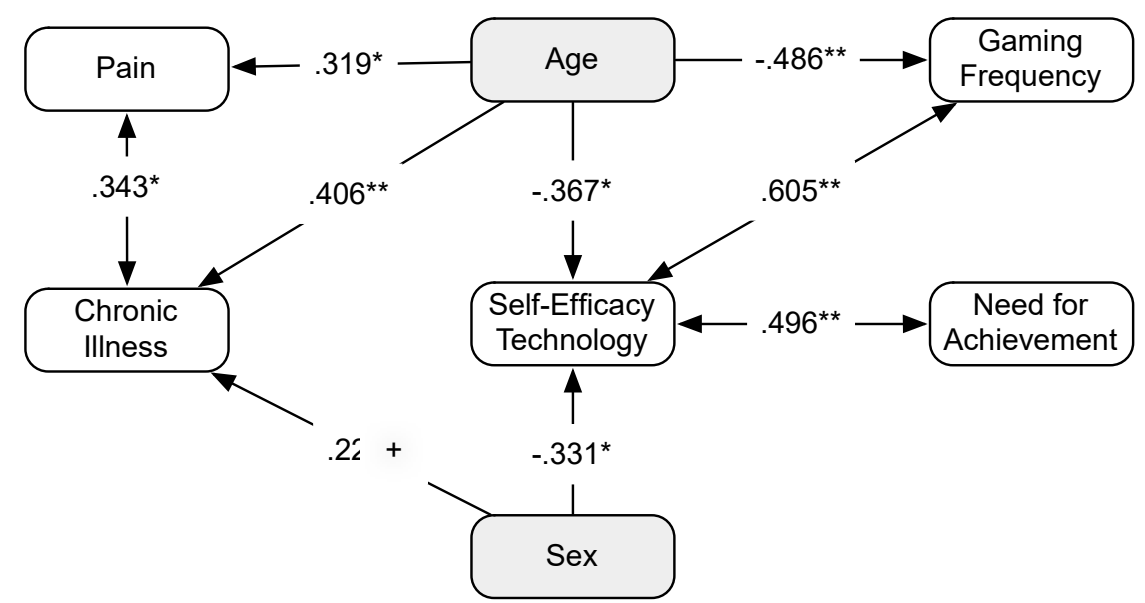

Figure 7. Interrelationships between the investigated user factors $\left({ }^{* *} \mathrm{p}<0.01 ;{ }^{*} \mathrm{p}<0.05\right)$.

\subsection{Results}

The results section is structured as follows. First, the overall effect of the game on the perceived pain levels and the perceived exertion is presented. Second, the factors that contribute to performance in the game are identified. Finally, the participant's intention to use and its contributing factors are analyzed.

\subsubsection{Effects of the Game}

1. Exertion: To understand the effect of the game on the perceived exertion, a repeated measures ANOVA with age and gender as independent variables, time as within-subject variable and perceived exertion as dependent variable was calculated. This calculation reveals that the perceived exertion doubles from $M=0.8(S D=1.2)$ to $M=1.7(S D=1.3)$ of 5 points and that this increase is statistically significant $\left[F(1,60)=13.3, p=.001, \eta^{2}=.182\right]$. Gender did not affect the change in exertion $[F(1,60)=0.5, n . s$.$] , but there is a significant effect of age [F(1,60)=7.7, p=.007$, $\left.\eta^{2}=.113\right]$. Specifically, the exertion of the juveniles increases from $M=0.7(S D=0.8)$ to $M=2.2(S D$ =1) of 5 points, whereas there is only a negligibly increase from $M=1(S D=1.5)$ to $M=1.2(S D$ $=1.1$ ) of 5 points for the elderly.

2. Pain: An investigation of the development of the perceived pain levels further reveals that there is a significant overall effect of the game on the perceived pain $\left[F(1,60)=20.2, p<.001, \eta^{2}=.252\right]$. On average across all participants, the perceived pain level decreased in the course of the exercise game. Although the absolute decrease from $M=0.5(S D=0.6)$ to $M=0.2(S D=0.3)$ of 5 points is rather small, the relative change of $-62 \%$ of is astonishing. Again, age $[F(1,60)=6.4, p=$ 
$\left..015, \eta^{2}=.097\right]$, but not gender $[F(1,60)=0.4$, n.s. $]$ affected the decrease in pain perception and the decrease is stronger for elderly $(-68 \%)$ than for the younger participants $(-33 \%)$. The other investigated factors, such as a chronic illness, did not or to a much smaller extend influence the change in perceived pain.

\subsubsection{Performance}

Merely, an 85 years old female participant had difficulties to use the game due to movability constraints. All other 63 participants picked 9 to 30 fruits in each level of the game with an average of $M=19.6(\mathrm{SD}=5.2)$ fruits per level $(M d=20)$. All investigated user diversity factors were found to influence the attained performance in the game (see Figure 8).

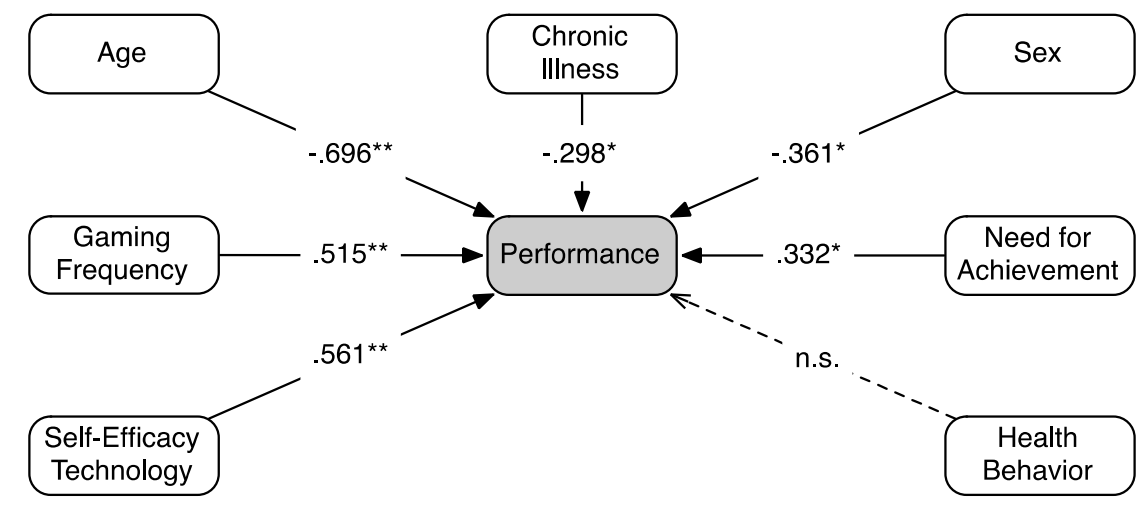

Figure 8. User factors contributing to performance $\left({ }^{* *} \mathrm{p}<0.01 ;{ }^{*} \mathrm{p}<0.05\right)$.

As the description of the sample has shown, all considered factors of user diversity are closely interrelated. Therefore, to untangle this net of dependencies and to identify the true drivers for performance, a multiple linear regression analysis is calculated. The user factors were the independent variables and the average performance across the three levels was the dependent variable.

The analysis revealed a linear model for performance based on age, need for achievement, and gender that explains over $63 \%$ of the variance in performance $\left(r^{2}=.63,63 \%\right)$. The model's parameters are given in the Table 2.

Table 2. Linear regression model for performance $\left(V I F_{\max }=1.39\right)$.

\begin{tabular}{l|cccc}
\hline \multicolumn{1}{c|}{ Factor } & B & SE B & $\beta$ & T \\
\hline (const) & 26.5 & 2.03 & & 13.04 \\
Age & -.17 & .02 & -.66 & -8.26 \\
Need for Achievement & 1.24 & .36 & .27 & 3.43 \\
Gender & -2.64 & .79 & -.27 & -3.34 \\
\hline
\end{tabular}

\subsubsection{Intention to Use}

Now, the important question is if and under which premises the game is likely to be used by future residents. This section provides two perspectives on this: First, the variables that govern the intention to use the game are identified. Second, the absolute evaluation of the game's evaluation is presented in regard to the identified influencing factors.

A correlation analysis shows that the intention to use the game is solely governed by the participant's prior gaming frequency $(\rho=.47, p<.001)$ and their self-efficacy in interacting with technology $(\rho=.31, p<.05)$. None of the other investigated facets of user diversity, e.g., age, gender, 
chronic illness or the need for achievement has a significant influence on the intention to use the game. A considerable finding is that the performance attained in the game is not meaningfully related to the projected later use $(\rho=.17, n . s$.$) . Hence, some people might express a desire to play or not to$ play the game again, regardless whether they were rather slow or rather fast in the game. Figure 9 illustrates the two variables influencing the projected use of the game.

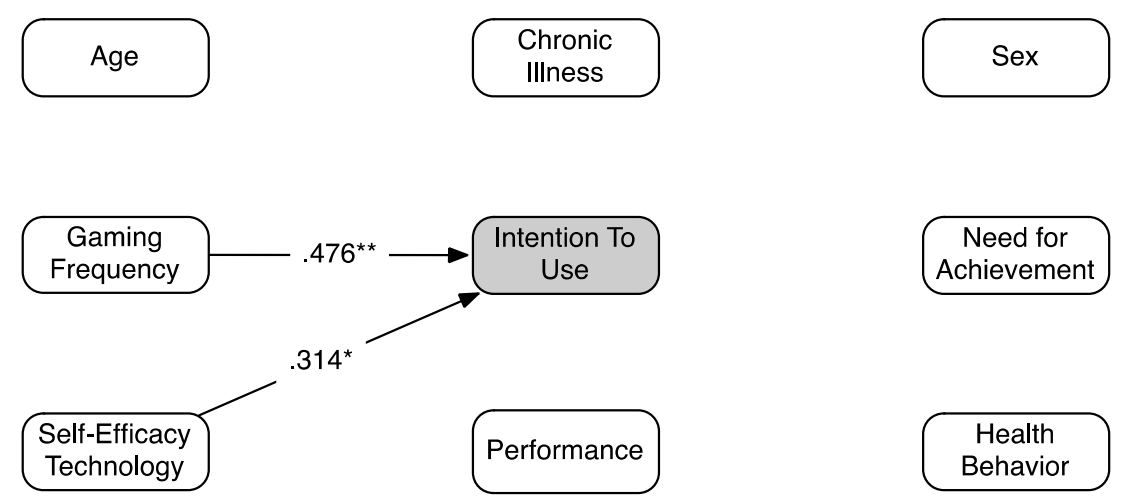

Figure 9. User factors contributing to intention to use $\left({ }^{* *} \mathrm{p}<0.01 ;{ }^{*} \mathrm{p}<0.05\right)$.

In the next step, a multiple linear regression revealed that the effect of self-efficacy in interacting with technology on intention to use fades, if controlled for gaming frequency. Hence, gaming frequency is the single significant influencing factor on intention to use serious games for healthcare in the technology augmented home environments.

Considering the absolute values of the intention to use the game, overall, the intention is rather high ( $M=3.9, S D=1.2$ out of 5 points) and way above the center of the scale ( 2.5 points). Specifically, the participants attested the game a high entertainment value $(M=4.6, S D=0.6$ out of 5 points $)$ and they expressed the wish to play the game again (replay value: $M=4.3, S D=0.9$ ). Yet, the desire to use this game in their very own home was much lower, but still above the center of the scale $(M=3, S D$ $=1.6$ out of 5 points).

As gaming frequency was identified as the factor that governs the intention to use this game in the future, it was further examined if the absolute evaluations differ. The overall intention to use was significantly higher for gamers $(M=4.2, S D=1)$ than for non-gamers $(M=3.5, S D=1.2)[F(1,62)=7$, $\left.p=.010, \eta^{2}=.102\right]$. However, both, gamers and non-gamers attested the game a similarly high $(M=4.6$, $S D=0.6)$ entertainment value $[F(1,62)=0.3, n . s$.$] . Moreover, the desire to play the game again did not$ differ significantly between the non- and gamers $[F(1,62)=3.4, n . s$.$] .$

According to the analyses, the participants are less inclined to use the game at their own home $(M=3, S D=1.6 / 5$ points $)$ and both GF-groups differ significantly $\left[F(1,62)=7.3, p=.009, \eta^{2}=.106\right]$. Gamers express a higher desire to play this game at home $(M=3.6, S D=1.3)$ than non-gamers $(M=$ $2.5, S D=1.8$ ). Surprisingly, the standard deviation on this question is considerably higher in comparison to the previous questions, which hints at different evaluations among the participants. Figure 10 illustrates the findings. 


\section{Evaluation of the game}

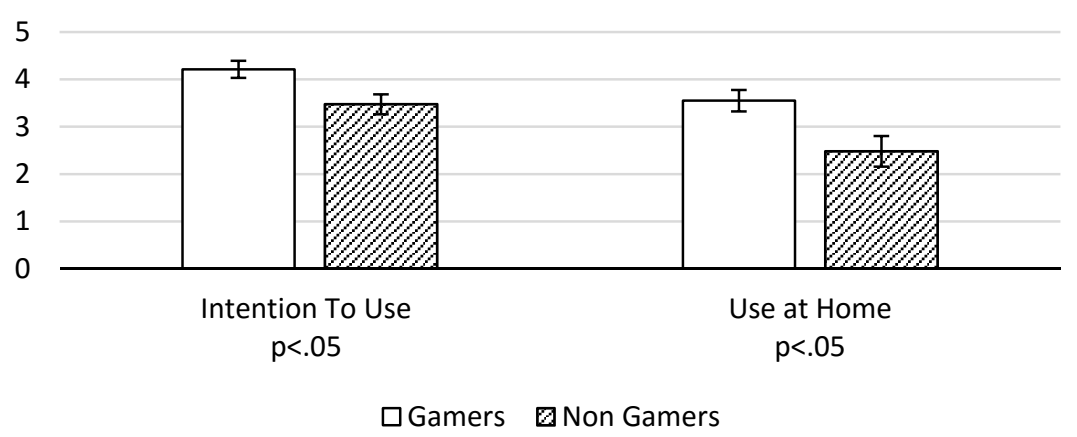

Figure 10. Overall evaluation of the serious exercise game by gamers and non-gamers.

\section{Discussion}

Smart homes and the embedded health-supporting technologies have an enormous potential to bring forward and facilitate some crucial mechanisms with respect to the consequences of demographic change. These so called eHealth technologies promise to deliver significant improvements in access to care, quality of care, and to increase the efficiency and productivity of the health sector [41, 42]. However, practical experience shows that the brilliance and novelty of existing technical solutions does not guarantee the successful diffusion of these innovations. Long-term success of smart health technologies depends on the sensitivity with which the users as well as their specific requirements, needs, and wishes are considered during the development and implementation process. In the following a résumé of the results of the both studies will be presented, interpreted and discussed in terms of smart health. The subsequent section deals with the limitations and future research.

\subsection{Summary and Discussion of the Results}

In this paper we introduced two different health-related applications, in which the broad acceptance and the intention to use these systems were under study. Both, chronically ill as well as healthy aged persons successfully interacted with the electronic health system implemented in a prototypic living room. In addition, a gaming environment was simulated that was supposed in a hedonic way to motivate the (older) inhabitants to keep active by physical exercise.

The current results show, that unlike previous trends in relation to the use of technological innovations, (where scientific studies have demonstrably revealed that young, mostly male individuals show significantly more technical interest, knowledge and skills) the greatest enthusiasm and willingness to use technology in terms of medical assistance systems in domestic environment emerges from the elderly and chronically ill people; regardless of gender. This finding originated especially from individuals with chronic heart diseases who did not only interact with the ambient system smoothly and in an intuitive way, but also showed a high motivation to use technology that is directly accessible in their living room and individually tailored to their personal needs, at the same time allowing to cope much easier with the disease. Their intention to use such ambient technology is higher than in healthy and middle-aged persons, however, according to the high average assessments of the perceived meaningfulness and fun, an overwhelming majority of the participants acknowledged the eHealth system as an useful, enriching, and sensible facility.

According the findings on serious games in technology augmented habitats which were examined through a strictly user-centered and participatory design methodology, it is advantageous to integrate serious games in ambient technology systems. Although, it has also been shown that not each person in old age displays the same fascination for gaming, technical aptitude and self-efficacy, suggesting a great diversity of individual factors in this group. This diversity among the users has to be considered for developing new and innovative healthcare solutions. Thus, the engineers need to 
be adequately trained to understand and consider the diversity in this regard. It could be learned moreover that basically all investigated user factors affect the attained performance in the game, however, age and the need for achievement were identified as the strongest predictors for the game performance. This finding is in line with the prior research $[43,44]$. Furthermore, from the users' evaluation it was evident that the inclination towards gaming and the gaming frequency are the strongest predictors for the intention to use the exercise game in the future. This finding seems obvious at the first sight, but is more deceptive at the second sight. On the one hand, exercise games are an excellent way to increase the fitness and overall health of the residents of technology augmented home environments. They increase their individual mobility and independence, and can contribute to the idea of successful aging. On the other hand, according to the presented results these exercise games are much more likely to be used only by gamers. Therefore, non-gamers are at risk to be excluded from this motivating, entertaining and preventive form of health-supporting intervention. Hence, future research must address alternative forms of technology-mediated exercising, for instance, by linking the generation of music or images with cognitive or physical exercises. Corresponding to the users' diversity, the different inhabitants of the technology augmented habitats have varying interests, therefore a multifaceted set of exercising applications with different connecting points (e.g., games, music, paintings) should be offered. Finally, but perhaps most importantly, the game affected the individual's perceived exertion levels, which indicates that the players were actually involved in the game and aimed at achieving a decent score. And even more importantly, playing the game had a strong positive effect on the perceived levels of pain. The young participants started at a rather low level of pain, permitting only little space for a further decrease. In contrast, the elderly reported a significant amount of initial pain that decreases over the course of the game. Of course, we do not speculate that exercise games can substitute any medical therapies, however, they might be a valuable addition. The theory of cognitive pain [45] is further backed by the present data. As a consequence, the medical therapy of a resident of healthsupporting home environments may be accompanied by a game-based exercise intervention. This form of entertaining distraction from the actual therapy then leads to a lower perceived pain, and an increased overall well-being.

In summary, the participants of both studies were extremely informative for the understanding of the ageing, the linked age-related ailments and the technology development. This can be outlined, based on three cornerstones of the age-appropriate technology developments.

- Holistic and interdisciplinary technology development

In contrast to the standard technology development as currently practiced, in which mostly medical or technical facets are in the central focus, there is an urgent need to develop novel, integrative models for the design of user-centered healthcare systems. New integrative concepts of health monitoring systems within ambient living environments are needed, which are suited to support the users individually (i.e., according to the users' profiles and needs), adaptively (i.e., in accordance with the age-related changes and/or depending on the course of disease), and sensitively (i.e., corresponding to the living conditions under all circumstances).

- Novel understanding of age and ageing

The technical development must be based on a sensitive concept of human needs that is specifically tailored to the requirements of the most frequent user group, the seniors. This could mean that the devices and technical systems then unveil their second sight: Smart health systems not being only compensatory for the negative effects of ageing (i.e., the general fragility as well as cognitive, physical, and structural deficiencies in older age) but rather completely vice versa. The support of the positive aspects of the ageing like life-experience, domain knowledge, skills and expertise, wisdom, and fun in the old age should be deeply anchored as benchmarks in a sustainable technology development [46]. As such, technology development then has the responsibility to empower elderly people as active parts of society.

- Integrating the users as experts in the whole process 
The most important modification in the traditional technology development approaches in the field of medical engineering is to include the users actively in the whole process, for which the technology is designed. A coherent, user-centered design of health-supporting devices integrated in home environments will result in ambient technology, which is not only functional in an engineering way of thinking, but also addresses the users' fundamental needs in terms of unobtrusiveness (non-stigmatizing design), ease of use, perceived usefulness, and the overall usability. Especially in case of Ambient Assisted Living and smart health systems this is a vital precondition. For the majority of us, the own home is the most intimate and confiding place, and technology that is integrated into this sensitive piece of identity must unconditionally adapt to the lifestyle and requirements of its inhabitant(s). It is all the more understandable that the involvement of end users, their perspectives, wishes and needs into every step of the development process plays a great role for a successful market launch.

\subsection{Limitations and Future Research}

The presented studies consider how smart health technology is perceived and how it is intended to be used by residents of technology enhanced habitats. Obviously, this view in the future is tainted with uncertainty. On the one side, the development of technology may follow different and currently unimagined paths. On the other side, future elderly may have different perceptions of technology in general and computer games in particular. It is evident that technology expertise is formed by individual upbringing and by the technology types that dominate in each generation. It follows that technology experience might differ between the generations [47] and there is a need to examine in how far different generations might get familiar with using such complex systems, adopting them as a natural part of their lives.

Another interesting line of research is to concentrate on gender effects. One reason is that women still have a higher life expectancy and live longer than their husbands or partners. Thus, in the next decades we can expect a superior number of women as senior users [48]. Besides, although slightly in contrast with the present study I, there is a strong empirical evidence that women show a lower interest in technology and a higher level of anxiety in the handling of novel and unknown technology. This goes hand in hand with a lower self-efficacy when using digital devices which makes women much more careful and reluctant in the interaction with technology [49]. From this point of view, smart health technologies might be a serious hurdle for this user group. However, regarding the use of social media women show a higher emotional involvement and social engagement in digital communication in comparison to men [50]; there is also a high social motivation to be friend with and stay in contact with family members or peers [51,52]. Thus, the higher involvement of women in the use of social media could be a powerful motivational anchoring or trigger point to attract them for the use of smart health applications at home.

A final point refers to the quality of the used prototype environment. Of course, the AAL environment that was created for experimental purposes was decisive for users to understand the impact and the visual appearance of smart health systems at home. In contrast to the normal user testing, in which devices are examined in isolation, it is mandatory that technology is examined in a realistic environment otherwise it is difficult for users to make fair evaluations [53]. Still, the used prototype had not the quality and maturity of the devices on the market. For example, the current version did not provide feedback on the accuracy of the gesture execution in the gaming scenario. As the temporal and spatial resolution of the motion sensors gets increasingly better, this offers excellent possibility to provide fine-grained feedback on the gestures' accuracy, which can be also embedded into the game (e.g., rewarding for precisely performed gestures).

\section{Conclusions}


Concluding, the presented studies have shown that smart health technologies in Ambient Assisted Living environments are an effective and entertaining method to monitor health parameters, maintain and/or improve the physical mobility, and increase the overall well-being of individuals in their living spaces. The presented findings provide evidence for a motivated attitude towards, and a high intention to use such technology solutions in their homes, especially in elderly and chronically diseased persons.

In the long term, health-supporting technology in domestic environments is meant to relieve the overstrained healthcare system and lighten the public budgets by decreasing the costs for inpatient treatments, long-term hospitalization and expenses for toilsome convalescence and rehabilitation.

As a final note, according to the resulting fun and high perceived meaningfulness, the combination of the entertaining games and the serious background gives a reason to conclude that Maria, who is autonomously monitoring her health parameters, might not only be able to enjoy her independent and characterized by self-determination and dignity life for longer, but also to improve her social network through the game-based interactions with her grandchildren.

\section{References}

1. Bloom, D. E.; Canning, D.; Fink, G. The greying of the global population and its macroeconomic consequences. Twenty-First Century Society 2010, 5(3), 233-242.

2. United Nations. World Population Prospects: The 2008 Revision. CD-ROM Edition - Extended Dataset United Nations, 2009.

3. Wilkowska, W. Acceptance of eHealth Technology in Home Environments: Advanced Studies on User Diversity in Ambient Assisted Living. Apprimus: Aachen, Germany, 2015.

4. Little, J. S.; Triest, R. K. Seismic Shifts: The Economic Impact of Demographic Change. An Overview. In Conference Series - Federal Reserve Bank of Boston [Internet]. 2001 [cited 2013 May 26]. p. 1-30

5. Leonhardt, S. (2006). Personal Healthcare Devices. In Mekherjee, S. et al., Eds., Malware: Hardware Technology Drivers of Ambient Intelligence; Springer, Dordrecht, Netherlands, pp. 349-370.

6. Lee, R. The demographic transition: three centuries of fundamental change. The Journal of Economic Perspectives 2003, 17(4), 167-190.

7. Holzinger, A.; Röcker, C.; Ziefle, M. From smart health to smart hospitals. In Smart health; Holzinger, A., Röcker, C., Ziefle, M., Eds.; Springer International Publishing, 2015, pp. 1-20.

8. Yan, H.R.; Huo, H.W.; Xu, Y.Z; Gidlund, M. Wireless sensor network based e-health system implementation and experimental results. IEEE Trans. Consum. Electron. 2010, 56(4), 2288-2295.

9. Demiris, G.; Tan, J. Rejuvenating home health care and tele-home care. In E-Health Care Information Systems: An Introduction for Students and Professionals; Tan, J. Ed.; Jossey-Bass: San Francisco, 2005; pp. 267-290.

10. Most frequent causes of dead, 2014: Available online: https://www.destatis.de/EN/FactsFigures/SocietyState/Health/CausesDeath/CausesDeath.html (accessed on 25 June 2016).

11. Klack, L.; Schmitz-Rode, T.; Wilkowska, W.; Kasugai, K.; Heidrich, F.; Ziefle, M. Integrated Home Monitoring and Compliance Optimization for Patients with Mechanical Circulatory Support Devices (MCSDs). Annals of Biomedical Engineering 2011, 39(12), 2911-2921, DOI: 10.1007/s10439-011-0407-1.

12. Venkatesh, V.; Thong, J.; $\mathrm{Xu}, \mathrm{X}$. Consumer acceptance and use of information technology: Extending the unified theory of acceptance and use of technology. MIS quarterly 2012, 36(1), 157-178.

13. Heidrich, F. Inhabitable Bits. Adaptive User Interfaces for Smart Environments. Apprimus: Aachen, Germany, 2015.

14. Kasugai, K. Raumgeist - Prototypen der raumunterstützenden Technik [Raumgeist - the prototypes of ambient supporting technology]. Apprimus: Aachen, Germany, 2014.

15. Brauner, P.; Holzinger, A.; Ziefle, M. Ubiquitous Computing at its best: Serious Exercise Games for Older Adults in Ambient Assisted Living Environments - A Technology Acceptance Perspective. EAI Endorsed Transactions on Serious Games 2015, 15(4), 1-12.

16. Röcker, C.; Kasugai, K. Interactive Architecture in Domestic Spaces. In: Wichert, R.; Van Laerhoven, K.; Gelissen, J., Eds.; Constructing Ambient Intelligence. AmI 2011 Workshops, Amsterdam, The Netherlands, 2011, CCIS 277(1). Berlin, Heidelberg: Springer, pp. 12-18. 
17. Beul, S.; Klack, L.; Kasugai, K.; Möllering, C.; Röcker, C.; Wilkowska, W.; Ziefle, M. Between Innovation and Daily Practice in the Development of AAL Systems: Learning from the experience with today's systems. Proceedings of the 3rd International ICST Conference on Electronic Healthcare for the 21st century, Casablanca, 2010.

18. Kasugai, K.; Ziefle, M. Ambient Intelligence im Living Lab. In Marquardt, G. (Ed.). MATI MenschArchitektur-Technik-Interaktion für demographische Nachhaltigkeit 2016, Fraunhofer IRB-Verlag, pp. 130139. ISBN: 978-3-8167-9472-1

19. Cooper, A. The Inmates Are Running the Asylum; Sams; 1999.

20. Brooke, J. SUS-A quick and dirty usability scale. Usability evaluation in industry 1996, 189, 4-7.

21. Cohen, J. Statistical power analysis for the behavioral sciences. Hillsdale, NJ: Erlbaum, 1988.

22. Zyda, M. (2005). From visual simulation to virtual reality to games. Computer 2005, 38(9), $25-32$.

23. Wittland, J.; Brauner, P.; Ziefle, M. (2015). Serious Games for Cognitive Training in Ambient Assisted Living Environments - A Technology Acceptance Perspective. Proceedings of the 15th INTERACT 2015 Conference, Germany, September 2015; Abascal, J., Barbosa, S., Fetter, M., Gross, T., Palanque, P., Winckler, M., Eds., LNCS 9296, Springer International Publishing, 453-471.

24. Knight, J. A. Physical Inactivity: Associated Diseases and Disorders. Annals of Clinical E Laboratory Science 2012, 42(3), 320-337.

25. Perez-Terzic, C. M. Exercise in Cardiovascular Diseases. Exercise and Sports for Health Promotion, Disease, and Disability 2012, 4(11), 867-873.

26. Ahlskog, J. E.; Geda, Y. E.; Graff-Radford, N. R.; Petersen, R. C. Physical exercise as a preventive or disease-modifying treatment of dementia and brain aging. Mayo Clinic Proceedings 2011, 86(9), Elsevier, 876-884.

27. Thayer, R. E.; Newman, J. R.; McClain, T. M. Self-regulation of mood: strategies for changing a bad mood, raising energy, and reducing tension. Journal of Personality and Social Psychology 1994, 67(5), 910 925.

28. Willey, J. Z.; Moon, Y. P.; Paik, M. C.; Yoshita, M.; DeCarli, C.; Sacco, R. L.; ... Wright, C. B. (2011). Lower prevalence of silent brain infarcts in the physically active: the Northern Manhattan Study. Neurology 2011, 76(24), 2112-2118.

29. De Schutter, B.; Vanden Abeele, V. Meaningful Play in Elderly Life. In 58th Annual Conference of the International Communication Association "Communicating for Social Impact", 2008.

30. Bandura, A. Self-Efficacy Mechanism in Human Agency. American Psychologist 1982, 37(2), $122-147$.

31. Busch, T. Gender differences in self-efficacy and attitudes toward computers. Journal of Educational Computing Research 1995, 12, 147-158.

32. Brauner, P.; Leonhardt, T.; Ziefle, M.; Schroeder, U. The effect of tangible artifacts, gender and subjective technical competence on teaching programming to seventh graders. Proceedings of the 4th International Conference on Informatics in Secondary Schools, Switzerland, 2010; Hromkovic, J., Královiè, R.; Vahrenhold J., Eds.; LNCS 5941, Springer, Berlin Heidelberg, 61-71.

33. Wilkowska, W.; Gaul, S.; Ziefle, M. A small but significant difference-the role of gender on acceptance of medical assistive technologies. HCI in Work and Learning, Life and Leisure, Austria, 2010; Springer Berlin Heidelberg, 82-100.

34. Arning, K.; Ziefle, M. Understanding Age Differences in PDA Acceptance and Performance. Computers in Human Behavior 2007, 23(6), 2904-2927.

35. Wilkowska, W.; Ziefle, M. Which Factors Form Older Adults' Acceptance of Mobile Information and Communication Technologies? HCI and Usability for e-Inclusion, Austria, 2009; Springer Berlin Heidelberg, 81-101.

36. Beier, G. Kontrollüberzeugungen im Umgang mit Technik [Control convictions in dealing with technology]. Report Psychologie 1999, 9, 684-693.

37. Schuler, H.; Prochaska, M. LMI: Leistungsmotivationsinventar [Need for Achievement Inventory]. Test hand manual, Hogrefe, 2001.

38. Borg, G.A.V. Psychophysical Bases of Perceived Exertion. Medicine And Science in Sports and Exercise 1982, 14(5), 377-381.

39. Davis, F.D.; Bagozzi, R.P.; Warshaw, P. R. User acceptance of computer technology: a comparison of two theoretical models. Management science 1989, 35(8), 982- 1003. 
40. Davis, F. D. Perceived usefulness, perceived ease of use, and user acceptance of information technology. MIS quarterly 1989, 13(3), 319-340.

41. Holzinger, A.; Dorner, S.; Födinger, M.; Calero Valdez, A.; Ziefle, M. Chances of increasing youth health awareness through mobile wellness applications. In Symposium of the Austrian HCI and Usability Engineering Group. Springer: Berlin Heidelberg, 2010; pp. 71-81.

42. Kleinberger, T.; Becker, M.; Ras, E.; Holzinger, A.; Müller, P. Ambient intelligence in assisted living: enable elderly people to handle future interfaces. In International Conference on Universal Access in Human-Computer Interaction; Springer: Berlin Heidelberg, 2007; pp. 103-112.

43. Fisk, A.D.; Rogers, W.A.; Charness, N.; Czaja, S.J.; Sharit, J. Designing for Older Adults: Principles and Creative Human Factors Approaches. Boca Raton, Florida, USA: CRC Press, 2009.

44. Fisk, A.D.; Rogers, W.A. Handbook of Human Factors and the Older Adult. Academic Press: San Diego, CA, 1997.

45. Melzack, R.; Wall, P.D. Pain Mechanisms: A New Theory. Science 1965, 150(3699), 971-979.

46. Ziefle M.; Schaar, A.K. Technology Acceptance by Patients: Empowerment and Stigma. In van Hoof, J.; Demiris, G; Wouters, E., Eds; Handbook of Smart Homes, Health Care and Well-being; Springer International Publishing, Switzerland 2014, pp.1-10.

47. Sackmann, R.; Winkler, O. Technology generations revisited: The internet generation. Gerontechnology 2013, 11(4), 493-503.

48. Barford, A.; Dorling, D.; Davey Smith, G.; Shaw, M. (2006). Life expectancy: women now on top everywhere. BMJ 2006, 332, 800.

49. Durndell, A.; Haag, Z. Computer self-efficacy, computer anxiety, attitudes towards the Internet and reported experience with the Internet, by gender, in an East European sample. Computers in human behavior 2002, 18(5), 521-535.

50. Sun, Y.; Wang, N.; Shen, X.L.; Zhang, J.X. Location information disclosure in location-based social network services: Privacy calculus, benefit structure, and gender differences. Computers in Human Behavior 2015, 52, 278-292.

51. Barker, V. Older adolescents' motivations for social network site use: The influence of gender, group identity, and collective self-esteem. CyberPsychology \& Behavior 2009, 12(2), 209-213.

52. Thelwall, M.; Wilkinson, D.; Uppal, S. Data mining emotion in social network communication: Gender differences in MySpace. Journal of the American Society for Information Science and Technology 2010, 61(1), 190-199.

53. Woolham, J.; Frisby, B. Social Care Online Search Social Care Online... Building a local infrastructure that supports the use of assistive technology in the care of people with dementia. Research Policy and Planning 2002, 20(1), 11-24.

(C) 2016 by the authors; licensee Preprints.org, MDPI, Basel, Switzerland. This article is an open access article distributed under the terms and conditions of the Creative Commons by Attribution (CC-BY) license (http://creativecommons.org/licenses/by/4.0/). 